7Universidade Tecnológica Federal do Paraná - UTFPR

Campus Ponta Grossa - Paraná - Brasil

ISSN: 1981-3686/v. 04, n. 01: p. 42-51, 2010

D.O.I.: $10.3895 / \mathrm{S} 1981-36862010000100005$
Revista Brasileira de Tecnologia

Agroindustrial

\title{
BARRA ALIMENTÍCIA COM ELEVADO VALOR PROTEÍCO: FORMULAÇÃO, CARACTERIZAÇÃO E AVALIAÇÃO SENSORIAL
}

\section{HIGH PROTEIN BAR: FORMULATION, CHARACTERIZATION AND SENSORIAL EVALUATION}

\author{
Tahis Regina Baú ${ }^{1}$, Mário Antônio Alves da Cunha ${ }^{2}$, Sibila Mariana Cella ${ }^{3}$, \\ Amanda Laís Jacobsen de Oliveira ${ }^{4}$, Jéssica Teixeira de Andrade ${ }^{5}$ \\ ${ }^{1}$ Universidade Tecnológica Federal do Paraná - UTFPR - Francisco Beltrão- Brasil tahisbau@utfpr.edu.br \\ ${ }^{2,3,4,5}$ Universidade Tecnológica Federal do Paraná - UTFPR - Pato Branco- Brasil mcunha@ utfpr.edu.br, \\ sibilacella@yahoo.com.br, jolieangel_216@hotmail.com, jandrade@yahoo.com.br
}

\begin{abstract}
Resumo
Barras alimentícias foram introduzidas no mercado há cerca de uma década como alternativa saudável de confeito. Paralelamente, o consumo de alimentos funcionais tem aumentando significativamente, contribuindo para o surgimento de novos produtos. Desta forma, o presente trabalho teve como intuito formular uma barra de cereal de elevado teor protéico e baixo conteúdo lipídico, buscando atender uma demanda crescente de consumidores. A caracterização físicoquímica da barra formulada revelou que o produto apresenta elevado conteúdo de proteínas $(15,5 \%)$ e de fibras (6,4\%), além de conteúdo lipídico relativamente baixo (2,23\%), o que sugere que o mesmo pode ser uma boa opção para suplementação nutricional. Foi verificada boa aceitabilidade do produto em relação aos atributos sensoriais cor, sabor, aroma, textura $e$ qualidade global, sendo observado índice de aceitabilidade global superior a $90 \%$.
\end{abstract}

Palavras-chave: Barra alimentícia; cereal; proteína; avaliação sensorial.

\section{Introdução}

A demanda por alimentos nutritivos e seguros está crescendo mundialmente, e a ingestão de alimentos balanceados é a maneira correta de evitar ou mesmo corrigir problemas de saúde (GUTKOSKI et al., 2007). De acordo com Freitas \& Moretti (2006), a associação entre barra de cereais e alimento saudável é uma tendência já documentada no setor de alimentos, o que beneficia o mercado destes produtos.

A preferência por alimentos de fácil consumo tem aumentado e as barras de cereais adquiriram grande espaço no mercado (FREITAS el al., 2005), exigindo das indústrias a busca por novos ingredientes e formulações, visando produtos com características físico-químicas e nutricionais capazes de propiciar benefícios à saúde (BOWER; WHITTEN, 2001).

As barras de cereais são elaboradas a partir da extrusão da massa de cereais de sabor adocicado e agradável, fonte de vitaminas, sais minerais, fibras, proteínas e carboidratos complexos 
(IZZO; NINESS, 2001), sendo consideradas essenciais para um bom funcionamento orgânico e, podendo prevenir e controlar determinadas patologias como obesidade, câncer e diabetes (SOUZA; SREBERNICH, 2008).

Trata-se de um produto obtido a partir da compactação de flocos de cereais como arroz, aveia, milho e cevada, xarope de glicose, açúcar, edulcorante natural ou artificial, gordura ou óleo vegetal, frutas secas, sementes oleaginosas, sal e estabilizantes, podendo ocorrer variação nos ingredientes de acordo com o sabor (SAMPAIO et al., 2004). De acordo com Matsura (2005), é necessário cuidado na combinação dos vários ingredientes da formulação, de forma a garantir que eles se complementem mutuamente em relação ao sabor, textura e propriedades físicas, particularmente no ponto de equilíbrio da umidade relativa.

Um alimento deve produzir satisfação e ser agradável ao consumidor. Isto é resultante da interação de diferentes parâmetros de qualidade sensorial. No desenvolvimento de novos produtos é imprescindível aperfeiçoar parâmetros, como forma, cor, aparência, odor, sabor, textura, consistência e a interação dos diferentes componentes, com a finalidade de alcançar um equilíbrio integral que se traduza em uma qualidade excelente e que seja de boa aceitabilidade (BARBOZA; FREITAS; WASZCZYNSKYJ, 2009).

Casé et al. (2005), reiteram afirmando que não basta saber que um determinado alimento é benéfico à saúde; a aparência, textura, odor e sabor têm papel importante na escolha e ingestão dos alimentos. Portanto, o presente trabalho, além da formulação e caracterização físico-química de uma barra de cereal com propriedades nutricionais atrativas buscou, também, sua avaliação sensorial.

\section{Material e Métodos}

Foram utilizados os seguintes ingredientes para a formulação da barra de cereais: glucose de milho, proteína texturizada de soja, aveia, uva passa, ameixa seca, kinako, leite em pó, albumina, açúcar mascavo, melaço de cana de açúcar, aromatizante, fibra de trigo e margarina.

\section{Formulação da Barra de Cereal}

Após uma seqüência de ensaios preliminares, os quais buscaram a combinação mais adequada dos ingredientes para obtenção de uma barra com boa constistência, foi obtida a formulação final da barra de cereais, apresentada na Tabela 01. 
Tabela 01 - Formulação da barra de cereais

\begin{tabular}{lc}
\hline Ingrediente & Formulação (g/100 g) \\
\hline Açúcar Mascavo & 15 \\
Albumina & 5,32 \\
Ameixa seca & 6,38 \\
Aromatizante & 0,04 \\
Aveia & 15 \\
Fibra de trigo & 1,4 \\
Glucose de milho & 21,53 \\
Kinako & 9,15 \\
Leite em pó & 5,32 \\
Margarina com 80\% de lipídeos & 3,2 \\
Melaço & 1,37 \\
Proteína texturizada de soja & 9,91 \\
Uva-passa & 6,3 \\
\hline
\end{tabular}

Para o preparo das barras, a glucose de milho, o açúcar mascavo, a margarina e o melaço foram misturados sob aquecimento brando. Paralelamente, os ingredientes secos foram misturados e adicionados ao xarope de aglutinação, sendo mantidos a uma temperatura de $37 \pm 2{ }^{\circ} \mathrm{C}$. A mistura final foi colocada em uma forma de aço inoxidável $(20 \mathrm{~cm}$ x $40 \mathrm{~cm})$, prensada com auxílio de um rolo de silicone e, após o resfriamento a temperatura ambiente $\left(25^{\circ} \mathrm{C}\right)$, foi cortada. A barrinhas obtidas foram, então, embaladas em filme de polietileno e envolvidas em papel alumínio.

\section{Caracterização físico-química do produto}

A formulação final do produto foi submetida a análises físico-químicas para determinação de umidade, cinzas, lipídios, proteínas e fibra dietética. Para a caracterização físico-química foram utilizados protocolos metodológicos descritos no Manual de Métodos Analíticos Oficiais do Lanara (LANARA, 1981).

\section{Avaliação sensorial do produto}

Os testes afetivos são empregados quando se procura conhecer o "status afetivo" dos consumidores com relação ao(s) produto(s), e para isso podem ser utilizadas escalas hedônicas. Dos valores relativos de aceitabilidade se pode inferir a preferência, ou seja, as amostras mais aceitas são as mais preferidas e vice-versa (FERREIRA, 2000).

A avaliação sensorial foi realizada por meio de Teste de Preferência/Aceitação (DUTCOSKY, 1996), sendo feita por uma equipe de 55 provadores não treinados de ambos os sexos com idades entre 15 e 65 anos, selecionados em função de consumirem produtos a base de cereais, disponibilidade e interesse em participar do teste. Escala Hedônica estruturada de nove pontos foi empregada para avaliar a aceitação dos provadores com relação aos atributos cor, sabor, aroma e textura isoladamente, e também a qualidade global, cujas notas por atributo variaram de gostei extretamente (9) a desgostei extremamente (1). A nota final de cada atributo foi determinada 
pela soma dos resultados obtidos a partir multiplicação do número de provadores que atribuíram a mesma nota ao atributo correspondente pelo valor numérico da escala hedônica (valores de 1 a 9). O Índice de Aceitabilidade (I.A) para cada atributo foi calculado conforme descrito por Teixeira; Meinert; Barbetta (1987), seguindo expressão abaixo:

$$
\begin{aligned}
& \begin{array}{ll}
I . A .(\%)=\frac{(A x 100)}{B} & \begin{array}{l}
\text { Onde, } \\
\mathrm{A}=\text { Nota média do atributo }
\end{array}
\end{array} \\
& \mathrm{B}=\text { Nota mais alta observada no atributo avaliado. }
\end{aligned}
$$

A intenção de compra dos provadores foi avaliada através de Teste afetivo, sendo utilizada uma escala de cinco pontos, que variou de certamente compraria (5) a certamente não compraria (1). Os resultados foram avaliados através das freqüências atribuídas na escala de intenção.

\section{Resultados e Discussão}

\section{Caracterização físico-química}

A caracterização físico-química da barra alimentícia formulada está demonstrada na Tabela 02.

Tabela 02 - Caracterização físico-química da Barra de Cereal

\begin{tabular}{cccccc}
\hline Parâmetro avaliado & $\begin{array}{c}\text { Umidade } \\
(\mathbf{g} / \mathbf{1 0 0} \mathbf{g})\end{array}$ & $\begin{array}{c}\text { Cinzas } \\
(\mathbf{g} / \mathbf{1 0 0} \mathbf{g})\end{array}$ & $\begin{array}{c}\text { Lipídios } \\
(\mathbf{g} / \mathbf{1 0 0} \mathbf{~})\end{array}$ & $\begin{array}{c}\text { Proteínas } \\
(\mathbf{g} / \mathbf{1 0 0} \mathbf{~ g})\end{array}$ & $\begin{array}{c}\text { Fibra dietética } \\
(\mathrm{g} / \mathbf{1 0 0} \mathbf{g})\end{array}$ \\
\hline Valores observados & 12,5 & 2,74 & 2,23 & 15,8 & 6,4 \\
\hline
\end{tabular}

A partir dos dados da tabela 2, pode-se observar que a barra produzida apresentou conteúdo de umidade relativamente baixo (12,5\%), valor este que está de acordo com a legislação Vigente. Segundo a Resolução RDC no 263, de 22 de setembro de 2005 (BRASIL, 2005), a umidade de barras de cereais deve ser inferior a 15,0\%. Outro aspecto importante é que o teor de umidade está dentro de parâmetros que permitem a manutenção da crocância (SERANTÓPOULOS et al., 2001); ao mesmo tempo que não favorece a proliferação microbiana, uma vez que além da baixa umidade o produto contém açúcar o que contribui para a redução da atividade de água. De acordo com Ribeiro (2003), alguns microrganismos estão envolvidos no processo de deterioração em cereais e seus produtos, os quais se desenvolvem sempre que encontram condições favoráveis de umidade e temperatura. Resultado similar de umidade foi encontrado por Freitas e Moretti (2006), que relatam umidade de 10,71\% ao analisar barras de cereal de alto teor protéico e vitamínico. Po outro lado, Brito et al. (2004), relatam valor inferior, cerca de 7,63\%. 
O teor de cinzas observado $(2,74 \mathrm{~g} / 100 \mathrm{~g})$ foi superior ao encontrado por Bueno (2005) de 1,18 g/100g. Contudo, Estévez et al. (1995) ao manufaturarem barra de cereais contendo gérmen de trigo, aveia e nozes encontraram conteúdo de cinzas semelhantes $(2,2 \mathrm{~g} / 100 \mathrm{~g})$.

Com relação ao conteúdo de lipídios, observou-se que o produto apresentou apenas 2,23 g/100g de matéria-graxa. Segundo Sampaio et al. (2004), no mercado são encontrados produtos com teores que variam de 4,0 \% a 12,0\%. Logo, pode-se constatar que a formulação elaborada apresenta baixo conteúdo lipídico, o que pode ser uma característica relevante, uma vez que os lipídios contribuem grandemente para o aumento do conteúdo calórico de um alimento.

Brito et al. (2004), ao quantificarem proteínas em barras de cereais comercializadas em Recife-PE, encontraram valores próximos a 4\%. De acordo com Freitas \& Moretti (2006), os produtos encontrados no mercado apresentam, em média, 4,4\% de proteínas. O mesmo autor, ao formular uma barra de cereal de elevado teor protéico e vitamínico, obteve um produto com 15,31\% de proteínas. Tal resultado assemelha-se ao encontrado neste trabalho $(15,83 \%)$ e sendo bastante superior aos produzidos em escala comercial.

O teor de fibra dietética verificado na formulação foi de $6,40 \mathrm{~g} / 100 \mathrm{~g}$. Diante disso, a barra de cereais desenvolvida pode ser classificada como um produto com alto teor de fibras, pois, segundo a ANVISA (BRASIL, 1998), para um alimento sólido ser classificado desta maneira, deve possuir, no mínimo, seis gramas de fibra em 100 gramas do produto pronto pra consumo.

\section{Avaliação Sensorial}

Considerando que o teste de aceitação por escala hedônica pode medir, com certo nível de segurança, o grau de gostar e a aceitação de um produto, é possível indicar através dos resultados desses testes, se o produto tem potencial para se tornar sucesso comercial (GRIZOTTO; MENEZES, 2003).

Existem opiniões contraditórias a respeito das características que mais influenciam a qualidade e aceitabilidade dos alimentos (ROMAN; MENDONÇA; SGARBIERI, 2009). Segundo Castro et al. (2007), para que um produto seja considerado como aceito, em termos de suas propriedades sensoriais, é necessário que obtenha um Índice de Aceitabilidade (I.A.) de no mínimo 70\%. O mesmo valor é considerado por Teixeira; Meinert; Barbetta (1987).

Todos os atributos de qualidade sensorial avaliados obtiveram I.A. superior ao recomendado na literatura. Foi verificado que os atributos sabor $(92,3 \%)$ e qualidade Global $(91,1 \%)$ apresentaram elevados índices de aceitabilidade, o que sugere a possibilidade de insersão comercial do produto. Kader (2002), relata que o sabor é o atributo mais importante e de maior ponderação, 
sobre aqueles que têm tradicionalmente consideração para o aspecto e a textura. Na Figura 01 estão descritos os valores do I.A para os atributos avaliados.

Figura 01 - Índice de aceitabilidade por os atributos sensoriais

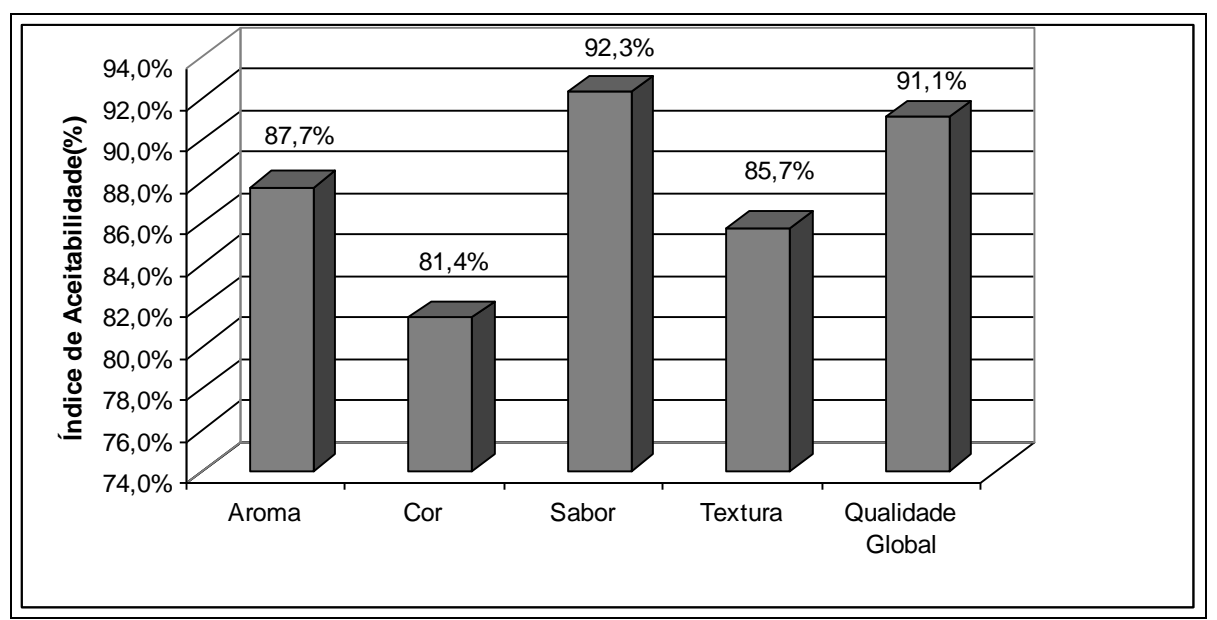

De acordo com Carvalho et al. (2006), a análise sensorial constitui um importante e eficaz meio para melhor conhecer a opinião do consumidor e sua intenção de compra em relação a um novo produto. Sendo de grande importância a verificação da intenção de compra do produto por parte do painel de avaliadores.

Na Figura 02 estão contidas as informações referentes à intenção de compra da barra de cereal produzida. Os dados revelam que mais de $80 \%$ dos avaliadores comprariam a barra de ceral, sendo que $38,18 \%$ afirmaram que certamente a comprariam e 43,64\% frequentemente comprariam, se fosse produzido em escala comercial. Outro dado que merece destaque é o fato que não houve nenhum provador indicando que certamente não compraria ou que raramente compraria tal produto.

Figura 02 - Intenção de compra dos provadores

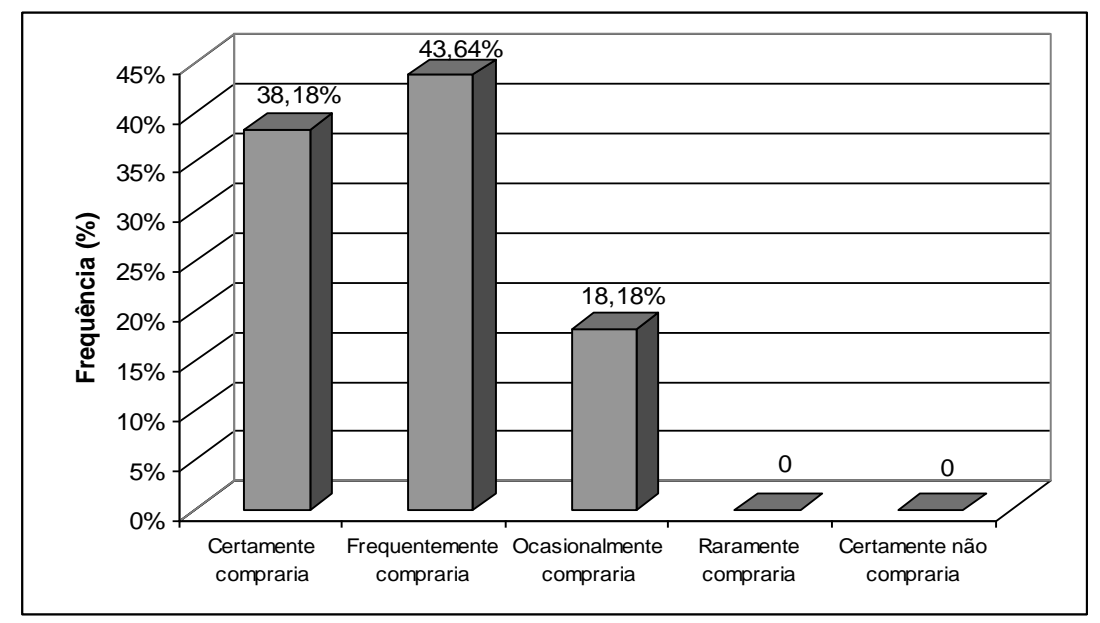

\section{Conclusão}

Os resultados obtidos no presente trabalho demonstram que o produto desenvolvido possui grande potencial de consumo, uma vez que todos os atributos de qualidade sensorial apresentaram 
índices de aceitabilidade superiores a $70 \%$, considerado adequado para ter boa perspectiva de aceitabilidade no mercado consumidor.

Além disso, o produto apresentou elevado valor nutricional, caracterizado pelo alto teor de fibras e proteínas, e baixo conteúdo lipídico, quando comparado a produtos similares disponíveis no mercado. Tais características vêm de encontro com os atuais anseios da população, que tem buscado consumir produtos menos gordurosos e ricos em fibras e proteínas. Dessa forma, seria possível considerar seguro o lançamento do produto no mercado consumidor.

\begin{abstract}
Cereal bars were introduced over a decade ago as an alternative of healthy confectionery. In addition, the consumption of functional foods has increased significantly, contributing to the emergence of new products. In this way, the present study aimed to development a cereal bar with high protein and low lipid content, to meet a growing consumers demand that seek a feeding more healthy. The physiochemical characterization of the cereal bar revealed that the obtained product presents high content of proteins $(15,5 \%)$ and fibers $(6,4 \%)$, besides had a relatively low lipidid content $(2,23 \%)$. This properties suggests that the product can be a good option for nutritional suppementation. Furthermore, the formuled product presented good sensorial acceptability by the color, flavor, aroma, texture and global quality. It was verified an aceitability index higher than 90 $\%$ for the global quality atribute.
\end{abstract}

Key-words: Cereal bars; protein; sensory evaluation.

\title{
Referências
}

BARBOZA, L.M.V.; FREITAS, R.J.S.; WASZCZYNSKYJ, N. Desenvolvimento de produtos e análise sensorial. Brasil Alimentos, n. 18, jan./fev., 2003. Disponível em: <http:// www.signuseditora.com.br/BA/.../18\%20\%20Desenvolvimento.pdf >, Acesso em: 20/12/2009.

BRASIL. Ministério da Saúde. Agência Nacional de Vigilância Sanitária. Portaria no 31, de 13 de janeiro de 1998. Aprova o Regulamento Técnico referente a Alimentos Adicionados de Nutrientes Essenciais. Disponível em: <http://elegis. anvisa.gov.br/leisref/public/showAct.php?id=64\&word=>, Acesso em: 10/05/2007.

BRASIL, Resolução RDC no 263, de 22 de setembro de 2005, Agência Nacional De Vigilância Sanitária - Anvisa; Aprova O "Regulamento Técnico Para Produtos De Cereais, Amidos, Farinhas E Farelos", Diário Oficial da União, Brasília (DF), de 23 de setembro de 2005.

BOWER, I. A.; WHITTEN, R. Sensory characteristics and consumer liking for cereal bar snack foods. Journal of Sensory Studies, v.15, n.3, p. 327-345, 2001.

BRITO, I. P.; CAMPOS, J. M.; SOUZA, T. F. L.; WAKIYAMA, C.; AZEREDO, G. A. Elaboração e avaliação global de barra de cereais caseira. Boletim do CEPPA, Curitiba, v. 22, n. 1, p. 35-50, jan./jun. 2004.

BUENO, R. O. G. Características de qualidade de biscoito e barra de cereais ricos em fibra alimentar a partir de farinha de semente e polpa de nêspera. 118 f. Dissertação (Mestrado em Tecnologia de Alimentos) - Programa de Pós-graduação em Tecnologia de Alimentos, Universidade Federal do Paraná, Curitiba, 2005.

CASÉ, F.; DELIZA, R.; ROSENTHAL, A.; MANTOVANI, D.; FELBERG, I. Produção de "leite" de soja enriquecido com cálcio. Revista de Ciência e Tecnologia de Alimentos, Campinas, v. 25, n. 1, p. 86-91, jan./mar. 2005. 
CARvalho, E. A.; Neto, B. A. M.; Aguiar, J. C.; CAldAS, M. C.; CAVAlCANTI, M. T.; MiYAJi, M. Desenvolvimento e Análise Sensorial de Sorvete de Massa Sabor Café. I Jornada Nacional Da Agroindústria. Anais, 2006.

CASTRO, L. I.; VILA REAL, C. M.; PIRES, I. S.; PIRES, C. V.; PINTO, N. A.; MIRANDA, L. S.; ROSA, B. C.; DIAS, P. A. Quinoa (chenopodium quinoa willd): digestibilidade in vitro, desenvolvimento e análise sensorial de preparações destinadas a pacientes celíacos. Revista Alimentos e Nutrição, v.18, n.4, p. 413-419, 2007.

DUTCOSKY, S. D. Análise Sensorial de Alimentos. 20 ed. Curitiba: Editora Universitária Champagnat, 1996.

ESTÉVEZ, A. M.; ESCOBAR, B.; VÁZQUEZ, M.; CASTILLO, E.; ARAYA, E.; ZACARÍAS, I. Cereal and nut bars, nutritional quality and storage stability. Plant Foods for Human Nutrition, v. 47, n. 4, p. 309-317, 1995.

FERREIRA, V.L.P. (Coord.). Análise sensorial - Testes discriminativos e afetivos. Campinas: Sociedade Brasileira de Ciência e Tecnologia de Alimentos, p. 73- 77, 2000.

FREITAS, D. G. F. Barras de cereais elaboradas com proteína de soja e gérmen de trigo, características físico-químicas e textura durante armazenamento. Archivos latinoamericanos de nutrición, v. 55, n. 3, p. 299-304, 2005.

FREITAS, D.G.C.; MORETTI, R.H. Caracterização e avaliação sensorial de barra de cereais. Revista Ciência e Tecnologia de Alimentos, v. 26, n. 2, p.318-324, 2006.

GUTKOSKI, L.C.; BONAMIGO, J.M.A.; TEIXEIRA, D.M.F.; PEDÓ, I. Desenvolvimento de barras de cereais à base de aveia com alto teor de fibra alimentar. Revista Ciência e Tecnologia de Alimentos, v. 27, n. 2, p. 355-363, 2007.

GRIZOTTO, R. K.; MENEZES, H. C. Avaliação da aceitação de "chips" de mandioca. . Revista Ciência e Tecnologia de Alimentos, v. 23, p. 79-86, 2003.

INSTITUTO ADOLFO LUTZ. Métodos físico-químicos para análise de alimentos, 4 ed., São Paulo, 2001, 1004p.

IZZO, M.; NINESS, K. Formulating Nutrition Bars with Inulin and Oligofructose. Cereal Foods World, v. 46, n. 3, p. 102-105, 2001.

KADER, A. Potential for improving quality and extending postharvest life of stone fruits by genetic manipulation. In: SEMINARIO INTERNACIONAL EN MEJORAMIENTO GENÉTICO DE FRUTALES DE CAROZO, 2., 2002, Santiago. Actualizaciones em mejoramiento genético y postcosecha y su relación con el mercado. Santiago: Universidad de Chile, 2002. p. 58-60.

LANARA. Métodos analíticos oficiais para controle de produtos de origem animal e seus ingredientes. Brasília: Ministério da Agricultura, 1981, 2v.

MATSURA, F. C. A. U. Estudo do albedo de maracujá e de seu aproveitamento em barra de cereais. Tese. Campinas, SP, 2005.

RIBEIRO, S. A. L.; CAVAlCANTI, M. A. A. Q.; FERNANDES, M. J. S.; LIMA, D. M. M. Fungos filamentosos isolados de produtos derivados do milho comercializados em Recife, Pernambuco. Revista Brasileira de Botânica, São Paulo, v. 26, n. 2, p. 223-229, 2003.

ROMAN, J.A.; MENDONÇA, S.N.T.G.; SGARBIERI, V.C. Avaliação físico-química, microbiológica, sensorial e atitude do consumidor de gelatina de elevado valor nutricional. Revista Alimentos e Nutrição, v.20, n.1, p. 41-51, jan./mar. 2009.

SAMPAIO, C. R. P.; FERREIRA, A. A.; CORREA, M. C. L. B.; PUMAR, M. Verificação da informação nutricional em rotulagem quanto à designação "light" de cereais em barra: uma pesquisa de mercado. In: Congresso Brasileiro de Nutrição (CONBRAN); Nutrição e Qualidade de Vida: enfrentando desafios. Anais, Campo Grande, 2004.

SARANTÓPOULOS, C. I. G. L., OLIVEIRA, L. M.; CANAVESI E. Requisitos de conservação de alimentos em embalagens flexíveis. CETEA, 2001, 213 p.

SOUZA, F.N.; SREBERNICH, S.M. Barra de cereal diet - desenvolvimento e otimização utilizando a metodologia de superfície de resposta nas variáveis dependentes textura, cor e atividade de agua. In: XIII Econtro de Iniciação Científica (PUC - Faculdade de Nutrição). Anais, Campinas, 2008. 
TEIXEIRA, E.; MEINERT, E.M.; BARBETTA, P.A. Análise sensorial de alimentos. Florianópolis: Editora da UFSC, 1987.

\section{Dados dos autores:}

\section{Nome completo: Tahis Regina Baú}

Filiação institucional: Universidade Tecnológica Federal do Paraná

Departamento: Coordenação de Alimentos

Função ou cargo ocupado: Técnica de Laboratório

Titulação: Tecnóloga em Alimentos, Especialista em Gerenciamento de Laboratórios

Endereço: UTFPR - Linha Santa Bárbara, s/n, Francisco Beltrão-PR, CEP: 85601-971

Telefones para contato:46 99125841 / 4635237111

e-mail:tahisbau@utfpr.edu.br

Nome completo: Mário Antônio Alves da Cunha

Filiação institucional: Universidade Tecnológica Federal do Paraná

Departamento: Química

Função ou cargo ocupado: Professor

Titulação: Doutor

Endereço: Via do Conhecimento Km 01, bairro Fraron, Pato branco, Paraná, Brasil, CEP 85501330.

Telefones para contato: (46) 32202596

e-mail:mcunha@utfpr.edu.br

Nome completo: Sibila Mariana Cella

Filiação institucional: Universidade Tecnológica Federal do Paraná

Departamento: Alimentos

Função ou cargo ocupado: Discente

Titulação: Técnico em Alimentos

Endereço: Via do Conhecimento Km 01, bairro Fraron, Pato branco, Paraná, Brasil, CEP 85501330.

Telefones para contato: (46) 32202596

e-mail: sibilacella@yahoo.com.br

Nome completo: Amanda Laís Jacobsen De Oliveira

Filiação institucional: Universidade Tecnológica Federal do Paraná

Departamento: Alimentos 
Função ou cargo ocupado: Discente

Titulação: Técnico em Alimentos

Endereço: Via do Conhecimento Km 01, bairro Fraron, Pato branco, Paraná, Brasil, CEP 85501330.

Telefones para contato: (46) 32202596

e-mail: amandaoliveira@yahoo.com.br

Nome completo: Jéssica Teixeira De Andrade

Filiação institucional: Universidade Tecnológica Federal do Paraná

Departamento: Alimentos

Função ou cargo ocupado: Discente

Titulação: Técnico em Alimentos

Endereço: Via do Conhecimento Km 01, bairro Fraron, Pato branco, Paraná, Brasil, CEP 85501330 .

Telefones para contato: (46) 32202596

e-mail:jandrade@yahoo.com.br 